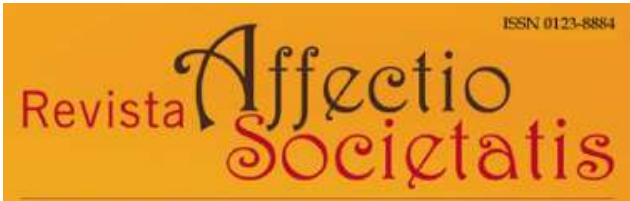

Departamento de Psicoanálisis I Universidad de Antioquia

Revista Affectio Societatis

Departamento de Psicoanálisis

Universidad de Antioquia

revistaaffectiosocietatis@udea.edu.co

ISSN (versión electrónica): 0123-8884

Colombia

2020

Edgar Miguel Juárez Salazar, Jesus De la Luz Castillo

La noción de trabajo en la teoría del discurso de Jacques Lacan

Revista Affectio Societatis, Vol. 17, N. ${ }^{\circ} 33$, julio-diciembre de 2020

Art. \# 1 (pp. 13-41)

Departamento de Psicoanálisis, Universidad de Antioquia

Medellín, Colombia 


\title{
LA NOCIÓN DE TRABAJO EN LA TEORÍA DEL DISCURSO DE JACQUES LACAN ${ }^{1}$
}

\author{
Edgar Miguel Juárez Salazar ${ }^{2}$ \\ Universidad Autónoma Metropolitana Xochimilco, México \\ edgar.jusan@gmail.com \\ https://orcid.org/0000-0001-6412-561X
}

Jesus De la Luz Castillo3
Universidad Autónoma Metropolitana Xochimilco, México
jesusdelaluzcastillo@gmail.com
https://orcid.org/0000-0002-5482-1205

DOI: 10.17533/udea.affs.v17n33a01

\section{Resumen}

El artículo parte de un recorrido por toda articulación discursiva. El discurel Seminario 17 de Jacques Lacan para so, como posibilidad de lazo social, es explicar los mecanismos por los cuales entendido como un modo de goce por el trabajo es un elemento esencial de el cual los sujetos son conminados a

1 El presente artículo ha sido resultado del trabajo en conjunto realizado para la acreditación del Diplomado en Psicoanálisis y Ciencias Sociales de la Universidad Autónoma Metropolitana.

2 Maestro en Psicología Social por la Universidad Autónoma Metropolitana Unidad Xochimilco (UAM-X). Licenciado en Psicología por la Universidad Michoacana. Profesor asociado de la Licenciatura en Psicología de la UAM-X y del Diplomado de Psicoanálisis y Ciencias Sociales de la misma institución. Profesor de la Maestría en Psicoanálisis en Dimensión Psicoanalítica impartiendo los cursos: Psicoanálisis y Filosofía y Psicoanálisis y Lazo Social. Practica el psicoanálisis en consultorio privado.

3 Estudiante de último trimestre de la Licenciatura en Psicología de la Universidad Autónoma Metropolitana Unidad Xochimilco. Diplomado en Psicoanálisis y Ciencias Sociales por la UAM-Xochimilco. Ha participado como coordinador y miembro de diversos eventos académicos con líneas afines a la teoría y práctica política. Ha sido traductor del francés al español de artículos sobre psicoanálisis. 
entrar en un mercado que administra su pérdida para poder establecer mecanismos de control. El texto muestra que el recorrido del trabajo y su relación con los objetos tiene un punto esencial en el establecimiento del discurso capitalista que permite distri- buir, de manera efectiva, el circuito gozante del sujeto y el intercambio del trabajo por plus de goce dentro de una economía política del deseo.

Palabras clave: deseo, discurso, goce, plus de goce, trabajo.

\section{THE NOTION OF WORK IN JACQUES LACAN'S THEORY OF DISCOURSE}

\section{Abstract}

This paper begins with a review of Jacques Lacan's Seminar XVII to explain the mechanisms by which work is an essential element of every discursive articulation. Discourse, as a possibility of social bonding, is understood as a mode of jouissance by which the subjects are ordered to enter a market that manages their loss in order to establish some control mechanisms. The text shows that the path of the work and its relationship with objects has an essential point in the establishment of the capitalist discourse that allows the effective distribution of the subject's circuit of jouissance and the exchange of work for surplus jouissance within a political economy of desire.

Keywords: desire, discourse, jouissance, surplus jouissance, work.

\section{LA NOTION DE TRAVAIL DANS LA THÉORIE DES DISCOURS DE JACQUES LACAN}

\section{Résumé}

Cet article se base sur l'examen du Séminaire 17 de Jacques Lacan pour expliquer les mécanismes par lesquels le travail devient un élément essentiel de toute articulation discursive. Le discours, comme possibilité de lien social, est compris comme un mode de jouissance par lequel les sujets sont sommés d'entrer dans un marché qui gère sa perte afin d'établir des mécanismes de contrôle. Le texte montre que le parcours du travail et sa relation avec les objets comporte un point essentiel dans l'établissement du discours capitaliste qui permet de distribuer, de manière efficace, le circuit de jouissance du sujet et l'échange du travail par plus- 
de-jouir au sein d'une économie poli- Mots-clés: désir, discours, jouissance, tique du désir. plus-de-jouir, travail.

\section{A NOÇÃO DE TRABALHO NA TEORIA DO DISCURSO DE JACQUES LACAN}

\section{Resumo}

$\mathrm{O}$ artigo parte dum percorrido pelo mostra que o percurso do trabalho e Seminário 17 de Jacques Lacan para explicar os mecanismos pelos quais o trabalho é um elemento essencial de toda articulação discursiva. $\mathrm{O}$ discurso, como possibilidade de vínculo social, é entendido como um modo de gozo pelo qual os sujeitos são obrigados a entrar num mercado que administra sua perda para estabelecer mecanismos de controle. $\mathrm{O}$ texto sua relação com os objetos têm um ponto essencial na constituição do discurso capitalista que permite a efetiva distribuição do circuito de gozo do sujeito e a troca do trabalho por mais-de-gozar dentro de uma economia política do desejo.

Palavras-chave: desejo, discurso, gozo, mais-de-gozar, trabalho. 
Quizá ya no se tenga miedo a los marxistas, pero se teme aún a ciertos no marxistas que no han renunciado a la herencia de Marx. Jacques Derrida. Espectros de Marx

\section{Prolegómenos a una teoría del discurso en Lacan ${ }^{4}$}

Para comenzar nuestro desarrollo nos ubicamos sobre el final de la década de los sesenta en la enseñanza del psicoanalista francés Jacques Lacan. Aunque podemos encontrar elaboraciones de Lacan sobre y desde el lenguaje en prácticamente toda su obra, en especial desde 1953, la potencia de su enseñanza sobre el discurso se acentúa y afina sobre el final de los años sesenta. En nuestro recorrido nos ubicamos fundamentalmente en el Seminario 17, en donde Lacan (2010/1969), a partir del año de 1969, formaliza puntualmente su idea de discurso entendiéndolo como "una estructura necesaria que excede con mucho a la palabra" (pág. 10). El discurso, por principio, es un excedente, un exceso en la relación con el mercado de los significantes. Efecto que no pasa desapercibido para el psicoanalista y que, en paralelo, permite el trazado y sostenimiento de la organización estructural del sujeto en el campo del lenguaje y que, en consonancia, establece diversos sentidos en su modo relacional y en su encadenamiento con otros elementos significantes.

En este mismo punto, Lacan (2010/1969) añade que el discurso "puede subsistir muy bien sin palabras" y que "subsiste en ciertas relaciones fundamentales" las cuales "no pueden mantenerse sin el lenguaje" (pág. 10). Desde esta pequeña síntesis, con la que abre su seminario sobre El reverso del psicoanálisis entre los años de 1969 y 1970, podemos apreciar que el discurso, como lo entiende Lacan, determina los víncu-

4 Denominamos teoría del discurso y no teoría de los discursos, o de los cuatro discursos como también se le conoce, porque su estructura es única, empero sus funciones son aquellas que cambian de lugar dando como resultado los respectivos discursos del amo, del analista, de la histérica, de la universidad y del capitalista. No siendo esto lo más importante sino los modos en que los discursos operan, como más adelante se verá. 
los sostenidos en la estructura limitada del lenguaje. Es decir, que las relaciones intersignificantes están sometidas y mantenidas de antemano por la estructura de la cual resulta imposible escaparse y que estriban en la ambivalencia real y simbólica del excedente.

Ulteriormente y a contrapelo, Lacan (1978/1972), en su Conferencia en Milán, regresa a preguntarse: “El discurso ¿Qué es?", y responde tajantemente, "un orden", puntualmente "una ordenanza", el discurso "es lo que (...) tiene función de lazo social" (pág. 37). Al hablar de función, Lacan muestra una necesidad por establecer aquellos elementos que permiten la mis en scene de la articulación de los componentes constitutivos de la función de lazo. Una función que tendrá sus efectos de permutabilidad en la articulación de la acción social mediante una exigencia del intercambio del orden de encadenamiento como producto de un proceso de significación con una lógica operativa de un conjunto no universalizable. ${ }^{5}$ Este modo de articulación desde el discurso es transmitida por el psicoanalista francés a lo largo de prácticamente todo su Seminario 17.

Lacan analiza el discurso esencialmente en sus giros. Desde "la función de significante en que se apoya la esencia del amo" (Lacan, $2010 / 1969,19)$ en el Discurso del Amo; pasando posteriormente por el caso Dora, el cual retoma para explicar que "lo que ella quiere es el saber como medio del goce" (Lacan, 2010/1969, 101) en la relación con el funcionamiento del Discurso de la Histeria, y señalando la insensata "pretensión de tener como producción un ser que piensa, un sujeto" en el Discurso de la Universidad (Lacan, 2010/1969, 189). En paralelo, también sugiere que el Discurso de la Universidad, como una neutralización efectiva del saber, es colocado sin falta en esos espacios de la universalización de la ciencia. El lector dará cuenta aquí que falta, cuando menos, una torsión del discurso. Lacan postula, en

5 Glynos (2013) sugiere que el discurso, desde la perspectiva lacaniana, debe analizarse tomando en cuenta los "puntos de referencia" que se encuentran asociados a una "narrativa fantasmática" que sostienen las "lógicas dominantes" (p. 189). El objeto $a$, conviene recordar en este punto, es un contenido articulable y articulado al fantasma por lo que la función de este intenta finiquitar la negatividad del deseo para presentar la posibilidad de la relación sexual (en Lacan) y social (en Marx). 
este recorrido, una subversión necesaria en la cual el psicoanálisis, como discurso, presenta una forma de reverso al discurso del amo moderno y, en consecuencia, una torsión de un cuarto de vuelta en la cual el objeto $a$ es el núcleo central del trabajo discursivo; en este sentido, el objeto $a$ incluso subvierte también la obturación de la verdad en el Discurso de la Universidad.

No obstante, es importante preguntarnos ¿cómo se origina el discurso? y ¿qué efectos tiene para precisar los alcances de su función? Para responder estas preguntas es trascendental partir del hecho de que la materia con la que trabaja Lacan está en homología con la de Marx: una materialidad simbólica que pertenece a una entidad estructural y universal que tiene de forma intrínseca un sostén en la disposición y encadenamiento significante. Por tanto, el elemento principal, sin el cual no podría haber discurso, es el significante y su trabajo y, adicionalmente, la imprescindible articulación que tiene como resultado efectos y producciones contingentes. ${ }^{6}$

Cabe subrayar, en una breve digresión, que discurso y práctica no remiten a la misma cosa en psicoanálisis. Podría decirse incluso que se alejan demasiado por momentos. Para el psicoanálisis de Lacan, el concepto de acto es mucho más interesante que la noción de práctica. En este sentido, todo acto discursivo se teje en el entramado de relaciones simbólicas, en el mercado de los significantes y produce un saber que, en consonancia, permite el establecimiento de diversos modos gozantes del Otro como ordenanza simbólica. La insistencia del valor primordial del significante necesita, por su misma contingencia, una repetición constante. Esta condición, además, muestra a la repetición como una secuencia en la línea ambivalente entre un automatón y una

6 En este sentido, el inconsciente se confirma material y económicamente por estar estructurado como un lenguaje: "para que empiece el inconsciente, basta una lira, la más barata de las mercancías o cualquier otro bien simbólico en cuya esencia textual ya está condensado todo lo estudiado por el psicoanálisis", menciona David Pavón-Cuéllar (2014, p. 26) a propósito de este materialismo simbólico. Así pues, esta idea ya estaba en Lacan (2010/1969, p. 191) confirmando así lo antes mencionado: "lo importante es que, si se puede hablar de goce es como algo vinculado con el origen mismo de la entrada en juego del significante". 
tyché, pues en el primero se catapulta y obtura lo real, mientras que en la segunda es lo real quien otorga la fuerza fundamental del acto. ${ }^{7}$

Se trata de un mecanismo repetitivo y gozante que opera discursivamente, y que Lacan (2014/1970, pág. 469) ubica en el lenguaje mismo, pues éste "innova con lo que revela del goce y hace surgir el fantasma" y, como enseñara en "El seminario sobre La carta robada", el significante materializa, en su encadenamiento cultural, la instancia de la muerte" (Lacan, 2009/1966, pág. 35). El discurso es entonces una actividad de intercambio y estriba en las coordenadas de los movimientos del saber. En paralelo, materializa el intersticio gozante del trabajo en función de la articulación del significante como mercancía sobre el ground del intercambio simbólico y la exigencia estructural y repetitivo-automática del goce del Otro, pero esto lo elaboraremos más adelante.

Retomando, el discurso implica entonces una relación singular con el goce como insistencia económico-repetitiva. Los significantes que aglutinan el discurso son trozos de materialidad susceptibles de ser intercambiados en un mercado. Estas mercancías significantes tienen, en su efecto discursivo, una lógica particular con matices de significación. Como observa Jean-Joseph Goux (1996, pág. 115), “la lógica del dinero", como un significante más entre tantos, "es la lógica misma, que opera en invariantes. La sustitución de una entidad por otra 'idéntica' también da fe de esta invariancia, que a su vez hace posible la repetición". El intercambio es una repetición gozante del trabajo muerto que ha tomado forma en el significante mercancía, por el cual un sujeto se desplaza entre modos de significación y entrelaza con la medida del acto su ex-sistencia como parlêtre.

Comprender el discurso en su sentido lógico permite concebirlo plenamente como función y como disposición que admite la produc-

7 Gabriel Lombardi (2015, p. 63) señala que la tyché prioriza un "accidente afortunado o desafortunado preferido o rechazado antes de haber sucedido" y estriba en la condición del "azar" y la pura contingencia, una posibilidad pequeña de elección por parte del sujeto hablante. Por su parte, Raúl Moncayo (2017, p. 247) muestra cómo la tyché, "representa un encuentro con lo real y se manifiesta en asociación libre. Los encuentros son cosas que uno sufre/goza en suspenso". 
ción gozante de un saber. En palabras de Esther Faye (2017, pág. 184), se trata de "una escritura lógica de pequeñas letras que inscriben un vínculo social particular que representa las relaciones de discurso y goce entre los sujetos como seres hablantes". En este sentido, no hay discurso, entre los cinco discursos planteados por Lacan, que escape a la disposición gozante del lazo social. De esta manera, toda inscripción enlazada por el discurso será condicionada por una economía de goce en relación con la movilidad del objeto pequeño $a$ y su contingencia desde lo real que escapa en parte a la simbolización totalitaria.

Ahora bien, el proceso por el que se construye el Discurso del Amo, en palabras de Lacan (2010/1969, pág. 17), es el siguiente: una vez surgido $S_{1}$ (Significante Amo), primer tiempo, ${ }^{8}$ se repite ante un segundo significante $\left(\mathrm{S}_{2}\right)$ como condición sine qua non de un saber. De esta puesta en relación surge el sujeto (\$), representado por algo, por "cierta pérdida", es decir por un producto denominado plus de goce, el "objeto $a$ ". Bajo el nombre de "Discurso del Amo", el primer discurso, y el más efectivo en las relaciones discursivas, es expresado por el psicoanalista francés de esta forma:

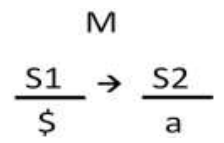

A estas letras las llamará "funciones propias del discurso" (Lacan, 2010/1969, pág. 97). Las cuales, a su vez, por decirlo de alguna forma, inauguran los lugares que ellas mismas ocupan de modo que la lectura de esos discursos puede entenderse como giros de lógica condicional en el sentido Si... Entonces que tendrán modos de organización e imposibilidades. Asimismo, a raíz de este primer discurso, Lacan nombrará a estos lugares de la siguiente manera (2010/1969, pág. 98):

8 Este primer tiempo que Lacan refiere no debe ser entendido en un sentido cronológico sino lógico de continuidad y ruptura. En una de las últimas clases del Seminario 17 dirá lo siguiente: “este significante único opera por su relación con lo que ya está ahí, articulado, de modo que sólo podemos concebirlo por una presencia del significante que ya está ahí, diría, desde siempre" (2010/1969, p. 164). Lo anterior haciendo alusión a una red de saber, a un sistema inconsciente previamente establecido. 


\section{$\frac{\text { deseo }}{\text { verdad }} \rightarrow \frac{\text { Otro }}{\text { pérdida }}$}

En paralelo, podemos señalar que la movilización del deseo sobre el saber del Otro produce un resto como pérdida, un trozo de real que se desprende por el proceso productivo. La función principal de deseo, como verdad del sujeto, es hacer trastabillar el condicionante del Otro para dar origen a la pérdida. A diferencia del Discurso del Amo, el Discurso Histérico se sostiene en la verdad causa del deseo mostrando la inconsistencia como excedente de goce. Hacemos una breve aproximación en este punto a una dialéctica económica marxiana imprescindible pues la duda histérica revela el secreto mejor guardado del sistema simbólico, es decir, la pérdida como excedente, plus de jouissance producido por un deseo en los límites de la negatividad en respuesta al saber del Otro, tal cual sucede con la plusvalía, como lo muestra Lacan (2008/1968) un año antes en su Seminario 16.

En este momento conviene recordar la influencia de Baruch Spinoza (2011/1678, pág. 156) sobre Lacan cuando el filósofo neerlandés plantea en su Ética, "el deseo es la esencia misma del hombre", a la cual Lacan (1967, pág. 7) hace referencia en su Seminario 14 cuando, a partir del establecimiento de un sentido del objeto $a$ desde la lógica del cross-cap aproxima puntualmente que "el deseo es la esencia de la realidad" gracias a la función de la causa del deseo del objeto a como ambivalencia positiva y negativa. Esto comprueba puntualmente dos cosas; la primera, de corte más contextual, estriba en que Spinoza no es un pensador de juventud para Lacan, de los años centrados en la personalidad y la locura, y que después olvidara, como afirma Roudinesco (1994, pág. 103). Por el contrario, la vigencia de Spinoza, como segunda aproximación, nos permite pensar que, para Lacan, el deseo figura, en cuanto a su función y su objeto causante, como el agente que viene a ordenarse y ordenar la realidad en los discursos y más particularmente en los modos de anudación del lazo social.

Es por esto que más adelante, en un segundo momento, no sin intención alguna, ni al azar, ni mucho menos expresando algún tipo de arbitrariedad que muchas veces se le adjudica, Lacan (2010/1969, pág. 182) cambiará el nombre de estos lugares de la siguiente forma: 


\section{$\frac{\text { agente }}{\text { verdad }} \rightarrow \frac{\text { trabajo }}{\text { producción }}$}

Es aquí donde encontramos lo que nos interesa: el trabajo como un lugar dentro del discurso; ¿porque Lacan hace este movimiento?, ¿qué quiere decir el trabajo como un lugar?, ¿por qué debería interesarnos esto? Es importante recordar lo que mencionábamos anteriormente: las funciones inauguran los lugares. Esto quiere decir que, si queremos saber más sobre el trabajo en tanto lugar, debemos preguntarnos primero por la función, o de manera más específica por la función que estructuró ese lugar, el cual es $\mathrm{S}_{2}$ que corresponde al saber. A lo sumo, añadiremos, a partir de aquí, la relación que existe entre el Otro y el trabajo al estudio de la función $S_{2}$, ya que inaugura a ambos como lugares que vehiculizan modos de producción determinados.

Que el lugar permita el establecimiento de la función es lo que instituye la entrada en un circuito económico entre saber y goce, que tendrá como efecto la circulación del trabajo como excedente negativo que es positivizado por el saber. Esto podemos observarlo de forma más clara en la función de circulación de la riqueza capitalista o en la supuesta neutralidad del saber en el intercambio del mercado en una Universidad. El trabajo como lugar exige una puesta en circulación de la producción, pues el sentido lógico del discurso reside precisamente en la movilidad del significante, tal como lo señalara muchos años antes Marx (2006/1867) en El capital con las mercancías. No hay mercancía que funcione sólo en su valor de uso, el mercado exige puntualmente un valor de cambio y esto conmina a delimitar que es gracias a la circulación que el ritual gozante de la producción, distribución y consumo puede continuar y perpetuarse.

El trabajo sería, entonces, la base central de un discurso que va cambiando de funciones respecto de los lugares que se ocupan en la cadena asociativa y para esto es indispensable que se hagan diversas transacciones dentro de un mercado simbólico. Hay un discurso, el del amo, porque existen otros cuatro discursos que movilizan el saber para mostrar el carácter contingente del mismo, sus modalidades de lazo social y los usos del plus-de-goce. Lo inconsciente sería, en efecto, un pasaje reprimido y escindido dentro del discurso, un saber que no se 
contenta con las cuitas y engaños efectivos de la razón mercantilizada sino se teje en el ímpetu sintomático del trabajo como formación desveladora. El inconsciente trabaja en oposición a esa razón y cuestiona, a su manera, el saber establecido por el discurso. Alenka Zupančič (2013, pág. 63) muestra, en oposición a los postulados sobre el inconsciente como un simple no saber, que el inconsciente es una "ausencia o falta de un saber reflexivo", en sus mismas palabras, "un no-saber en la forma de un saber" que estriba en "pasar de contrabando" a la conciencia. El trabajo de represión, así como el trabajo pulsional, señalan dos fuerzas que son administradas por los modos en que el objeto causa del deseo se articula gozante y fantasmáticamente en el parlêtre.

En este sentido, es en el lugar de la producción en donde Slavoj Žižek (2004, pág. 34) ubica el resto indivisible más allá de la simple "producción discursiva". Como todo trabajo, desde su explotación y alienación, el discurso tiene un resto indivisible y no reducible; el plus de goce que termina por sostener algo del saber discursivo y simbólico que no puede ser capturado por el lazo social. Se trata del espacio ausente o hueco que organiza desde la parcialidad y la imposibilidad de decirlo todo, una relación reprimida entre saber y dominación que recae en un objeto. Es, en otras palabras, un núcleo ausente pero efectivo pues se encuentra tejido en el prisma de la realidad simbólicodiscursiva. Esto nos lleva a sugerir que el saber del amo se apropia del plus de goce constriñendo una elección forzada que permite positivizar el trabajo muerto en el sistema simbólico mediante la insistencia del discurso y su carga ideológica como organizadores de una realidad articulada. Como refiere atinadamente Bracher (1994, pág. 111), "los sistemas articulados de saber derivan del posicionamiento de los sistemas del sujeto en ciertos puntos dentro de ellos y, por lo tanto, establecen una cierta 'identidad' para el sujeto. Estos posicionamientos implican un cierto sentido de identidad, un cierto goce y una cierta estructuración del inconsciente".

Así Žižek (2013, pág. 156), en El resto indivisible, parece complementar lo anterior al subrayar que "cada objeto positivo que encontramos en la realidad sustituye su original perdido". Todos esos objetos parciales parecen obtenerse al entregar nuestra fuerza de trabajo a los modos políticos de explotación del Discurso del Amo; éste con su 
totalidad fatua atascada de savoir faire recupera y comercializa un saber del proletario, y se reactualiza con el estudiante universitario mediante el semblante de un saber neutro de la Universidad y del Capitalista con la renovación perpetua de este objeto perdido e indivisible.

En la misma línea, Mladen Dolar (2017, pág. 77) afirma, con una aproximación puntual desde Hegel y que vincula a la noción de inconsciente como hueco desde Freud, que el filósofo alemán se obstina en hacer de "la hiancia", a contra pelo, "un principio habilitador" que mostraría "la productividad de lo negativo". En otras palabras, el discurso como lazo busca hacer del deseo un trabajo redituable en la positividad cuasi-universal del entramado simbólico-imaginario. Sin embargo, la potencia negativa del deseo como fuerza de la pulsión hace también un trabajo contingente en el establecimiento positivo del discurso. Una resistencia vinculada a la verdad mediante una subversión y no como una revolución del deseo. La relación inmediata del discurso con el saber y el goce es la muestra evidente de que el trabajo alienado del sujeto en la conciencia tiene la posibilidad de ser subvertido por las formaciones del inconsciente que también trabajan como veremos más adelante.

\section{La tríada trabajo-Otro-saber}

El trabajo es un concepto fundamental en la obra freudiana. Podemos, por principio, recurrir a los "Tres ensayos de teoría sexual", donde Freud (2000/1905) precisa a la pulsión, concepto fundante del psicoanálisis y no deconstruible del mismo, como una exigencia de trabajo. ${ }^{9}$ Asimismo, es posible detectar esta insistencia en los trabajos metapsicológicos de Freud (2000/1914), en particular en su "Introducción del narcisismo" y en "Más allá del principio de placer" (Freud, 2000/1920). No pretendemos adentrarnos en el contenido de estos escritos freudianos pero la precisión estriba en que el trabajo no sólo aparece en la obra freudiana en sus desarro-

9 Véase Jorge Alemán (2001) en torno a la pulsión como elemento indeconstruible del psicoanálisis. 
llos propiamente sociales como "El malestar en la cultura" (Freud, 2000/1930) o "El porvenir de una ilusión" (Freud, 2000/1927). Esta insistencia lacónica descansa en delimitar que, en el recorrido freudiano, sería oportuno recordar las precisiones hechas por el médico de Viena en torno al trabajo y en particular ser consecuentes con una relectura puntual de sus escritos. En este punto resulta ineludible retornar a la precisa inserción del concepto de trabajo en la conocida "Interpretación de los sueños". Para Freud (2000/1900), el sueño debe analizarse en las claves del trabajo de condensación y trabajo de desplazamiento: un inconsciente que "labora" y que establece las coordenadas del deseo.

Si el inconsciente trabaja lo hace porque habla, toda forma discursiva centrada en el deseo del Otro es también un modo de hablar. Como sugiere Samo Tomšič (2012, pág. 104), "Freud modifica la figura del hablante y del trabajador, ça parle (eso habla) como decía Lacan pero debemos añadir ça travaille (eso trabaja)" ${ }^{10}$. La tarea, en palabras de Freud (2000/1900, pág. 285), estriba en "investigar las relaciones entre el contenido manifiesto y los pensamientos latentes del sueño, y pesquisar los procesos por los cuales estos últimos se convirtieron en aquel". No se trata, en este sentido, sólo del trabajo del sueño sino también de sus procesos que relacionan el contenido latente con el contenido manifiesto del sueño. El sueño tiene un sentido y una lógica que, aunque se encuentren reprimidos, siempre tendrán una posibilidad de mostrar sus efectos.

Puede pensarse entonces en un retorno lacaniano sobre el trabajo a partir del Seminario 16 como una consecuencia de otro retorno a Freud, a través de Marx, un poco más tardío. Es verdad que los conceptos de $\mathrm{S}_{2}$ (Saber), Otro y trabajo de Lacan no aparecen aquí

10 Es oportuno precisar en este punto que ça designa en francés al Ello como instancia psíquica. No deja, con esto, de parecernos singular la aproximación de Deleuze y Guattari (2010/1973, p. 306) cuando señalan, en El anti-Edipo, que "el deseo pertenece al orden de la producción"; sin embargo, la característica de máquina que piensan ambos autores se aleja de la negatividad del deseo mismo pues olvida la condición articulatoria del trabajo: ça parle. Para ampliar esta discusión véase Andreja Zevnik (2016 p. 106), en particular el subcapítulo "Desiring the World". 
escritos de la misma forma, más esto no impide que no sean palpables como a continuación lo mostraremos. La primera vez que Lacan (2010/1969, pág. 11) habla de la función $S_{2}$ en el Seminario 17 lo hace en relación con $\mathrm{S}_{1}$ : "S1 debe considerarse como el significante que interviene. Interviene sobre una batería significante (S2) que nunca, de ningún modo, tenemos derecho a considerar como dispersa, como si no formara ya la red de lo que se llama un saber". En otras palabras, $\mathrm{S}_{2}$ forma la red lógica de un saber, de un sistema inconsciente, el cual Freud descubre por vía de las articulaciones del trabajo de condensación y desplazamiento: la metáfora y metonimia de Lacan. En este sentido, $\mathrm{S}_{2}$ sería la base del sueño $\mathrm{y}$, a su vez, el modo en que éste se configura a nivel del lenguaje. ${ }^{11}$

Posteriormente, Lacan (2010/1969, pág. 13) dirá, a manera de recordatorio, que "el saber es el goce del Otro" explicando que "de lo que se trata es de una articulación lógica" en donde "la intervención del significante lo hace surgir como campo". Esto, a primera vista, parecería cíclico si lo comparamos con la cita anterior de Lacan. Sin embargo, Lacan está haciendo un énfasis particular al señalar el surgimiento del Otro como campo (o lugar) debido a la intervención y relación significante, estableciendo así una diferencia apenas perceptible entre la función $\mathrm{S}_{2}$ y el Otro como lugar, lugar de intercambio y redistribución constante de objetos simbolizados en una red lógica. Por tanto, la teoría del discurso obedece, desde nuestra perspectiva, a una sola teoría económico-política del significante. Los movimientos están en función de un saber y del objeto $a$, con un excedente permiten un intercambio a partir de la constante movilidad de los componentes del discurso y no sólo de los lugares. Hay, en efecto, una economía política en la teoría lacaniana del discurso gracias a la distribución del goce.

Lacan había señalado ya en el Seminario 16 la homología entre su objeto $a$ y la plusvalía marxiana. Que Lacan haga esta precisión permite ubicar las condiciones de posibilidad del objeto y los desplazamientos gozantes sobre este. La relación entre campo y saber

11 La apreciación de Samo Tomšič $(2012$, p. 99) es aún más aguda, pues, para él, si el inconsciente trabaja, entonces "el inconsciente es capitalista", al estar inserto en la misma estructura gozante, como se verá páginas más adelante. 
es mediada por un goce que tiene una disposición en el objeto que se desprende y deviene mortífero. En otras palabras, la entrada del sujeto en el mercado del saber tiene un excedente muerto, un trabajo que no es más la vida del trabajador sino la disposición e intercambio de mercancías como trabajo atravesado y comercializado por la muerte. Como delimita Tomšič (2015, pág. 204), "la estructura se reduce a una paralaje: desde la posición del objeto excedente" y "parece que los valores y los significantes interactúan sin ninguna referencia al sujeto". En el punto más recalcitrante de toda esta organización que problematiza la posibilidad de la relación social se confirma "la fascinación contemporánea con la autonomía absoluta del capital ficticio y la tesis psicoanalítica sobre el 'autismo de goce' o la 'perversión generalizada' que privilegian esta posición".

Podemos decir, entonces, que el contenido manifiesto y el contenido latente surgen, desde Lacan, como campo, como Otro, debido a la intervención $S_{1}$ en la batería significante del $S_{2}$. Es el modo de relación con el goce el que precisa un desenvolvimiento de un saber que hace trabajar positivamente los engranajes del discurso. La triada entre trabajo, saber y el Otro es fundamental, ya que es la posibilidad de hacer lazo, pero, en paralelo, el fundamento mismo del intercambio de objetos. Desde Freud (2000/1900, pág. 313) puede localizarse lo anterior en una frase muy puntual sobre el trabajo, a saber, "el desplazamiento y la condensación oníricos son los dos maestros artesanos a cuya actividad podemos atribuir principalmente la configuración del sueño". La artesanía de lo simbólico, utilizando la metáfora freudiana, alberga elementos constitutivos que dejan traslucir un saber, no sólo del sueño como formación del inconsciente, sino también de los entramados en los que el sujeto es presa de una economía política de la lengua.

El trabajo en el discurso es, en efecto, un trabajo administrado, como lo son también los sueños al pasar por la represión y la desfiguración onírica; como el síntoma que con su trabajo catapulta la verdad sobre la voluntad del sujeto o como cualquier otra formación del inconsciente. No obstante, en el discurso, como señala Zupančič (2006, pág. 155), se "articula también la jouissance junto con el significante y lo postula como un elemento esencial de toda discursividad. Además, 
este reconocimiento de la dimensión discursiva del goce presenta la dimensión política del psicoanálisis". No sólo podríamos remitirnos a la mítica frase de Lacan (1967, pág. 424) "el inconsciente es la política", quizás es oportuno agregar antes y gracias al trabajo del inconsciente que este, como tal, se define también en una economía política del deseo y del goce.

Por otro lado, en Lacan, el trabajo no solo tiene el mismo sentido que en Freud, posee, además, el soporte y la potencia del pensamiento hegeliano a partir de la conocida dialéctica del amo y el esclavo. Hablamos de un apoyo muy particular pues Lacan, como es conocido, leyó el Hegel de Alexandre Kojève, y esta traducción sin duda es una formación del equívoco por el cual Lacan comenzó un acercamiento singular al pensamiento de Hegel. ${ }^{12}$ Para Lacan, el trabajo no da cuenta de la verdad del amo, tal como lo dice Kojève (2006/1982) en La dialéctica del amo y del esclavo en Hegel. ${ }^{13}$ Lacan (2010/1969, págs. 83-84) señala este hecho en el Seminario 17 de la siguiente manera:

La caracterización del Discurso del Amo como el que comporta una verdad oculta no quiere decir que este discurso se oculte, se parapete [...]. Está claro que su verdad se le oculta, y un tal Hegel articuló que la obtiene del trabajo del esclavo. Sólo que, ya ven, este discurso de Hegel es un discurso de amo que se basa en la sustitución del amo por el Estado [...]. Parece que resultó definitivamente refutado mediante algunos hallazgos, los de Marx. No estoy aquí para comentarlo y no voy a hacer un apéndice, sino que mostraré simplemente hasta qué punto, desde el mirador psicoanalítico, podemos cómodamente poner en duda, de entrada, esto de que el trabajo engendre en el horizonte un saber absoluto, ni siquiera algún saber.

12 Recientemente vieron la luz, gracias a la pericia investigadora de Juan Pablo Luchelli (2016), cinco cartas de Lacan a Kojève que matizan con mayor profundidad la cercana relación que tuvieron ambos pensadores.

13 "Su verdad es, en cambio, la Conciencia no-esencial; y la actividad no-esencial de esta última. [Es decir: la verdad del Amo es el Esclavo y su Trabajo. En efecto, los otros no reconocen al Amo en tanto que Amo sino porque hay un Esclavo; y la vida del Amo consiste en el hecho de consumir los productos del Trabajo servil, de vivir, de y por ese Trabajo]" (Kojève, 1982/2006, p. 10). 
Por lo cual, más adelante, añade, "si el saber es medio de goce, el trabajo es otra cosa" (Lacan, 2010/1969, pág. 84). Esta puntualización lacaniana nos permite sostener con más fuerza que la homología entre Marx y Lacan estriba también en cómo el saber termina siendo un medio para la realización del goce de un sistema. En Marx podemos definirlo desde un trabajo alienado y en Lacan desde un trabajo mercantilizado en el saber del Otro. Pero, ¿cuál es entonces la diferencia entre el trabajo concebido por Lacan y el trabajo más allá de como lo concibe Hegel a partir de su finalidad de producir? Pues bien, como punto de encuentro diremos que el trabajo no sólo produce objetos materiales concretos, sino también plus-de-jouissance, tal como lo señala Lacan. Esta idea no se la adjudica a sí mismo como un descubrimiento sino a Marx, quien es el que lo revela denunciando la expoliación de la plusvalía en El capital y quien es, como es conocido, el verdadero inventor del síntoma. En palabras del psicoanalista francés, "lo que Marx denuncia en la plusvalía es la expoliación de goce. Y, sin embargo, esta plusvalía es la memoria del plus-de-goce, su equivalente del plus de goce" (Lacan, 2010/1969, pág. 85).

Sin embargo, esto no basta. Para completar esta idea es preciso regresar un poco y remitirnos al Seminario 16. De un Otro al otro, donde Lacan menciona la condición que se necesita para que exista la producción de plus-de-goce, diciendo:

Marx parte de la función del mercado. Su novedad es el lugar donde sitúa el trabajo. No es que el trabajo sea nuevo, sino que sea comprado, que haya un mercado del trabajo. Esto le permite a Marx demostrar lo que hay de inaugural en su discurso, y que se llama la plusvalía. (Lacan, 2008/1968, pág. 16).

En otras palabras, lo que Lacan muestra aquí es que, tan solo dentro del mercado, el producto del trabajo adquiere una característica especial que es la plusvalía como elemento intrínseco de la circulación de las mercancías, es decir, el elemento central del valor de cambio. Un objeto susceptible de vincularse a una explotación consecuente del trabajo humano y como efecto de la transformación del valor de uso en movilización administrada por un saber mercantilizado. 
Es por este motivo que un análisis del inconsciente no puede prescindir de la política, pues en el objeto $a$, como producto discursivo del trabajo, estriba un modo de saber sobre el deseo y su circulación. Por ello la subversión del Discurso del Analista reside, por el contrario, en no contentarse con el semblante y exponer el carácter irreductible que causa deseo. Como muestra Kiarina Kordela (2007, pág. 41), “el saber es saber de las causas, ni el capital ni el signo pueden conocerse si se examinan de forma aislada, como campos separados, ya que ambos son causados por una misma sustancia" y, de este manera, "el análisis de la economía capitalista, por lo tanto, debe incluirse entre las ciencias cuyo objeto es un modo de la sustancia diferencial, como el análisis de todos los campos que implican el examen del lenguaje".

Es necesario en este punto considerar que, en sus manuscritos de juventud, Marx (2009/1844, pág. 116) señalaba ya puntualmente que "mediante el trabajo enajenado no sólo produce el hombre su relación con el objeto y con el acto de la propia producción como con poderes que le son extraños y hostiles, sino también la relación en la que los otros hombres se encuentran con su producto". De suerte que toda posibilidad de lazo social es dependiente de los modos de trabajo por los cuales el sujeto se relaciona con los objetos y, desde luego, en los modos de alienación del mismo. Aunque el filósofo de Tréveris explora fundamentalmente tres tipos de alienación, a saber, de la actividad, del objeto y social, la alienación del objeto desde el fetiche de la mercancía permite anudar la condición enigmática del objeto $a$ lacaniano con la mística objetal que Lacan (2015/1960) trazara desde la noción de agalma en el Seminario 8 y que, en este momento, se rearticula gracias a su ambivalencia como excedente y como nudo discursivo. Esto puede encontrarse también desde Freud, pues para Pavón-Cuéllar (2017, pág. 50), en "ambos pensadores, Freud y Marx, un objeto deviene fetiche en tanto se aparece para retener todo lo que el sujeto pierde: la pérdida de su alma, su personalidad excluida, su vida sacrificada o la prohibición de la pulsión".

Por tanto, es muy importante recalcar que el trabajo para Lacan es un lugar por medio del cual el inconsciente se vincula con la posibilidad de lazo social, con los engranajes del trabajo alienado a un sistema mercantil, debido a que el trabajo se engancha en el espacio 
movilizador del saber mercantil que, por medio de la materialidad simbólica del significante y su organicidad y adecuación en el Otro, produce un excedente redituable y enigmático; un plus-de-goce que sólo es posible admitir si hay una mercantilización del trabajo y la explotación del mismo mediante una alienación. En este punto, y como una anotación paralela, Marx (2010/1845, pág. 19) refiere, en La ideología alemana, que "la producción de las ideas y representaciones de la conciencia, aparece al principio directamente entrelazada con la actividad material y el comercio material de los hombres, como el lenguaje de la vida real"14.

En efecto, la conciencia del sujeto es, desde la relación entre el trabajo y el orden simbólico, un producto alienado. El inconsciente es también, en respuesta, un modo en el que el trabajo manifiesta una ruptura con los modos de mercantilización del saber por vía del mismo significante, en la misma clave lógica y en toda su fuerza. Se trata de lo que Jean-Claude Milner (2016/1995, pág. 151) refiere como "trabajo del inconsciente, trabajo del significante", es decir, "trabajo indiferenciado y sin frases, es el trabajo sin cualidades". Es precisamente por esta condición que Lacan (2012/1971, pág. 75) sostiene que "cualquiera que sea el sitio que ocupemos [en el discurso], jamás pescamos nada". Es el exabrupto contingente del inconsciente quien muestra la falla del lazo social que sólo puede ser puesta en duda, más allá de un discurso que hace semblante, por la fuerza del trabajo del inconsciente y la falta constitutiva del sujeto.

Recurrimos nuevamente a la exploración homológica, partiendo de Marx (2006/1867, pág. 133) y Lacan, ya que si el objeto plus de goce es constitutivo del Discurso del Amo y también del capitalista, entonces se valida la noción marxiana por la cual "el trabajo se compenetra y confunde con su objeto" mientras, al mismo tiempo, "absorbe" gracias a los "medios de producción y a otros valores de uso", otros "valores de uso de procesos de trabajo anteriores". Esto puede augurar la perpetuidad del saber que se recicla por los procesos del trabajo y la insistencia del capitalista por reorganizar la pérdida y el

14 Las cursivas son nuestras. 
trabajo muerto en el sistema simbólico, el paso de un trabajo concreto a un trabajo abstracto en donde, como sugiere Walter Benjamin (2016/1982, pág. 668), "se encierra para Marx toda la miseria de la sociedad productora de mercancías".

Es en este sentido indispensable pensar cómo Freud lleva al límite el descubrimiento de un sistema inconsciente en el trabajo de sueño; encontrando los únicos movimientos del lenguaje sobre los que se estructura el inconsciente, ${ }^{15}$ siendo esta tal vez la razón principal por la cual Lacan localiza al trabajo y al Otro en el mismo lugar en su teoría del discurso como efecto del saber $\left(\mathrm{S}_{2}\right)$. Esto se constata cuando asegura que "en el nivel del discurso universitario, el objeto $a$ viene a parar a un lugar que está en juego cada vez que esto se mueve, el de la explotación más o menos tolerable" (Lacan, 2010/1969, pág. 192). ${ }^{16}$ Con lo anterior, el pequeño $a$ resulta un objeto que, siguiendo a Wajcman (2001, pág. 42), se divide en la "dialéctica de lo singular y lo plural"; un objeto social y consciente producido del exterior a lo interior.

El discurso en Lacan es un mecanismo laboral-utilitario que sólo puede ser desvelado por una fractura en las articulaciones y los lugares. Si bien Freud sienta las bases de un trabajo del inconsciente en el sueño y Marx en la alienación y cosificación del trabajo, era indispensable ubicar la figura del objeto causa del deseo para poder potenciar la antagónica invención marxiana del síntoma y el carácter ambivalente de la plusvalía. En relación con esto, Žižek (2012, págs. 214-215) afirma: "ni Marx ni Freud son realmente capaces de pensar el antagonismo, en última instancia, ambos lo reducen a una característica de la realidad (social o psíquica)"; sin embargo, "la lógica diferencial del estructuralismo" que acontece con Lacan, sí permite pensar más allá a partir de la "imposibilidad a partir de la cual la realidad se construye".

15 Así pues, no es casualidad que Freud (2000/1911), en su análisis del caso Schreber, haya tomado como recurso teórico el trabajo de formación delirante como análogo al trabajo de sueño para explicar la formación de la paranoia del presidente Schreber. Véase la página 37 y la nota al pie de página número 3 del escrito.

16 Las cursivas son nuestras. 
Finalmente, para comprender la triada entre el trabajo, el saber y el Otro resulta indispensable partir de la literalidad del pensamiento freudiano y también de la aproximación lógica de Lacan, pues ambos elementos disciernen el alcance de un trabajo en función del goce de aquel que tiene el saber y los efectos sobre quien lo detenta. Desde luego que estas coordenadas sirven para matizar que no sólo se encuentra en juego un simple establecimiento de un lazo social, sino toda una forma económico-política del psiquismo en conjunto que hilvana los modos de demanda que establece el Otro sobre el trabajo del sujeto.

\section{Breve epílogo o un beyond work en Lacan}

La relación entre el trabajo y el discurso en Lacan puede permitir expandir los campos de estudio, teórica y políticamente hablando, del psicoanálisis un poco más ya que, a partir de la lectura que hace Lacan de Marx vía Freud, podemos decir que el trabajo no es una característica exclusivamente dependiente de la economía, sino que la inscripción de todo aquello que podemos llamar relación social permite dar cuenta de que, en sus alcances y también como imposible, reconoce que el "saber" no sólo opera sino que "trabaja" (Lacan, 2010/1969, pág. 53), saber inconsciente y consciente que trabaja más allá del antagonismo, es el inconsciente capitalista trabajando, como muestra Tomšič. Asimismo, para Pluth (2020, pág. 231), “Lacan también consideró cómo los dos mecanismos lingüísticos principales de la metonimia y la metáfora moldearon la forma en que somos, más notablemente en términos de deseo y nuestras identificaciones". El uso de la lingüística en Lacan explica un vaciamiento del sentido para, en las mismas coordenadas, poder subvertir la potencia de la significación opresiva.

Con lo anterior, Lacan se permite comenzar a elaborar el discurso como lazo, ya que es clara la necesidad articulatoria a partir del núcleo vacío dejado por el objeto $a$. Esta astucia lacaniana no sólo permite reconocer la existencia de los registros sino modos de articulación del saber con la ideología dominante burguesa. Aunque pueda 
parecer un recurso común en el pensamiento marxista en torno a la clase, la propuesta de Lacan dista de pensar sólo en una oposición porque se centra también en cómo producir un cuarto de vuelta al saber discursivo del orden simbólico. Para comprender esto se debe seguir en toda su literalidad la célebre inscripción de Lacan (2009/1972, pág. 143): "No hay metalenguaje", a la que llega después de hacer un periplo por la condición de lo real incesante en su escritura. Pero si no hay metalenguaje, tampoco hay más allá de la materialidad simbólica, y esto abre nuevas posibilidades lógicas de anudamiento para las identificaciones políticas, para los modos de explotación y para hacer con el malestar del sujeto producido por el sistema simbólico de la cultura. Más allá de esto, la imposibilidad de la relación sexual es, por señalar un ejemplo fundante del psicoanálisis, el reflejo sobre la administración fantasmática y de significación por la cual el sujeto intenta omitir o obturar ese exceso de trabajo sexual ya reprimido por el esfuerzo cultural.

De esta manera, el psicoanálisis de Lacan y su teoría del discurso no pueden pensarse sin la ausencia productiva de negatividad y positividad. Lacan vio en el psicoanálisis, en opinión de Samo Tomšič (2019, pág. 18), "no sólo un intruso sino también un reverso del Discurso del Amo" que se "esfuerza por subvertir el dominio que sostiene el modo capitalista de producción y contratacar sus dañinas consecuencias". La formalización lacaniana del Discurso del Amo en un sentido lógico puede operar como una subversión, un cuarto de vuelta, sobre la disposición de los modos gozantes del capitalismo actual. En este sentido, su noción de trabajo formalizada por el discurso abre la brecha de posibilidades políticas contingentes. ${ }^{17}$

Así pues, debemos agregar que el trabajo para Lacan conlleva algo más que una fuerza o un gasto de energía en el sentido en que Marx concibe la "fuerza de trabajo" o en el sentido en que Freud percibe la investidura de objeto o la pulsión. Esta forma de concebir el trabajo del psicoanalista francés se encuentra bastante clara en El Seminario 17 cuando recurre a la física para explicar que el trabajo no se

17 El trabajo de Laclau y Mouffe (2011), en este sentido, da cuenta de los alcances contingentes del significante. 
limita a ninguna fuerza, a ningún gasto de energía, pues de lo que se trata, en el fondo, es de la aplicación de operaciones lógicas sobre el mundo de los significantes:

\begin{abstract}
¿No saben ustedes que la energética no es nada más, por mucho que crean los corazones ingenuos de los ingenieros, que la aplicación sobre el mundo de la red de los significantes? Les desafío a que comprueben que bajar 500 metros sobre sus espaldas un peso de 80 kilos y, una vez que lo han bajado, volver a subirlo 500 metros, da cero, ningún trabajo. Hagan la prueba, pónganse manos a la obra, verán como comprueban lo contrario. Pero si aplican ahí los significantes, es decir, si entran en la vía de la energética, es absolutamente cierto que no ha habido ningún trabajo (Lacan, 2010/1969, pág. 51). ${ }^{18}$
\end{abstract}

Es así que para Lacan de lo que se trata es de operaciones lógicas dadas por relaciones significantes particulares, las que traen consecuencias no solo sobre el mundo, sino también sobre los modos gozantes del sujeto. Podemos decir, entonces, que lo relevante en la teoría del discurso de Lacan es la forma en que la función que esté ocupando el lugar del agente (o deseo) se relaciona con la función que esté ocupando el lugar del trabajo administrado (u Otro). Esto se puede apreciar más claramente en un momento durante la "Primera Impromptu de Vincennes" donde Lacan (2010/1969, págs. 215-216) habla del Discurso de la Universidad y del Discurso del Amo, ahí declara:

El discurso universitario está en la pizarra y el saber ocupa, en la pizarra, un lugar arriba y a la izquierda ya asignado en un discurso

18 Un par de páginas antes menciona Lacan (2010/1969, págs. 47-48): “Por qué nos restringimos a este manejo del significante y su eventual articulación? Se trata de algo que está en los mismos datos del psicoanálisis. Quiero decir que se encuentra en lo que se le manifestó a un espíritu tan poco introducido en esta clase de elaboraciones como podía serlo un Freud, teniendo en cuenta su formación, que conocemos, del tipo de las ciencias parafísicas, fisiología armada con los primeros pasos de la física y, especialmente, de la termodinámica". Lacan da cuenta así del estrecho vínculo entre el mundo de la física y la operación lógica que un analista debe llevar a cabo en sesión. 
precedente. Porque lo que tiene importancia en lo que está escrito son las relaciones, dónde ocurre algo y dónde no ocurre. Si empiezan por poner en su lugar lo que constituye esencialmente el discurso del amo, a saber, que ordena, que interviene en el sistema del saber, pueden plantearse la cuestión de saber qué quiere decir si el discurso del saber, por este desplazamiento de un cuarto de círculo, no tiene necesidad de estar en la pizarra porque está en lo real.

Subrayamos que lo importante son las relaciones entre funciones porque es ahí "donde ocurre o no algo". Este hecho nos permite profundizar un poco más en la forma en que Lacan concibe al trabajo como un lugar y no como una práctica, como un lugar al cual se le articula una función y no como mera actividad espontánea.

Dicho todo lo anterior, podemos añadir de forma más puntual que para Lacan el trabajo, como efecto de la función $S_{2^{\prime}}$, es un lugar no solamente articulado sino también articulable (que solo se encuentra arriba a la derecha en la estructura del discurso) ${ }^{19}$ por su relación con $\mathrm{S}_{1}$ o con cualquier función que esté en el lugar de agente; convirtiéndolo así en el lugar que vincula el espacio subjetivo y social, dando pie a una continuidad (topo)lógica que ya vislumbraba Freud en "La interpretación de los sueños".

Existen puntos aún más sombríos dentro del Seminario 17 sobre el trabajo en la teoría del discurso de Lacan, así como la relación de este con los niveles de la impotencia (abajo) y la imposibilidad (arriba) en la estructura del discurso, que requerirían un examen más profundo y reflexivo que aquí no podemos brindar. Empero, antes de finalizar este texto, es necesario traer a consideración el argumento más subversivo del psicoanalista francés en relación con trabajo y el discurso, pues buscamos rescatar el sentido subversivo del psicoanálisis porque, de manera breve y concisa, Lacan (2010/1969, pág. 181) declara cuál ha sido, desde su perspectiva, el motivo principal por el cual el Discurso del Amo moderno, en su forma capitalista, ha mantenido su dominación:

19 "En efecto, como en todos los otros cuadraditos o esquemas de cuatro patas, siempre es éste de aquí, el de arriba a la derecha, el que trabaja" (Lacan, 2010: 110). 
La finalidad de estas observaciones es que se sorprendan y se planteen al menos una pregunta concerniente al discurso del amo: ¿cómo dicho discurso, que se entiende tan maravillosamente bien, puede haber mantenido su dominación? Tal y como lo prueba este hecho, que explotados o no, los trabajadores trabajan. Nunca, desde que la humanidad existe, se ha concedido tanto honor al trabajo. Hasta se excluye la posibilidad de que no se trabaje. Es todo un éxito, desde luego, de lo que llamo el discurso del amo. Para ello, ha tenido que sobrepasar ciertos límites. Para decirlo todo, llega hasta eso, en una mutación que traté de señalarles. Espero que se acuerden, y si no se acuerdan -es muy posible-, voy a recordárselo enseguida. Hablo de aquella mutación capital, también ella, que da al discurso del amo su estilo capitalista. ${ }^{20}$

Al señalar que Marx inventa el síntoma, Lacan (2010/1969, pág. 88) sabe perfectamente que lo que está en juego en el Discurso del Capitalista no es solamente el uso no pagado del trabajo del proletario, sino también el "saber que el rico no paga". Un proletario y un trabajador se distinguen precisamente en la entrada del primero en un engranaje técnico y productivo que usa su trabajo vivo para poder administrar trabajo muerto. ${ }^{21}$ En palabras de Pavón-Cuéllar (2009, pág. 22), "la vida que el proletario pierde sin obtener nada a cambio, Marx la relaciona con una plusvalía que él concibe, en su materialismo dialéctico, como el valor simbólico que el capitalista gana, gratis, a cambio del disfrute real que el proletario pierde". Es por esta razón que la reinvención del capitalismo como nueva modalidad del Amo estriba en no mostrar y obturar la pérdida del proletario con el engaño de nuevos objetos fetichizados por el saber que se reinventan. Como sugiere Lacan (2014/1970, pág. 458), “la plusvalía, es la causa del deseo de la que una economía hace su principio, el de la producción extensiva y por tanto insaciable de la falta-en-gozar".

Para el marxismo, el giro que la interpretación de Lacan podría aportar sería el siguiente: la relación particular de las funciones del Discurso del Amo, en su modo capitalista, no solo compra y vende

20 Las cursivas son nuestras.

21 Slavoj Žižek (2010), en El sublime objeto de la ideología, desarrolla ampliamente el postulado lacaniano en su capítulo: "Cómo inventó Marx el síntoma". 
trabajo (el lugar que vincula el espacio subjetivo con el social), sino que ha ido más allá articulando, comprando y vendiendo las funciones mismas, gozando sin pagar por ellas. Por último, y en consonancia con lo anterior, aludimos a Tomšič (2020, pág. 303) cuando exhibe que "una contribución importante del psicoanálisis en general, y de la teoría de Lacan en particular, a la crítica del capitalismo consiste en su examen sistemático de la relación entre el discurso y el goce". Tal vez por esta condición Lacan apunta hacia un discurso que no fuera del semblante, retomando el ¿qué me quiere el Otro? (che vuoi?) cuando entramos en su entramado discursivo intercambiando nuestro modo de gozar por la respuesta de un excedente cargado de malestar. O peor, permanecer $\mathrm{y}$ reducirse como sujeto finalmente a un significante que se moviliza en ese engranaje de mercancías en donde el semblante predomina.

\section{Referencias}

Alemán, J. (2001). La introducción a la antifilosofía. Virtualia (2), 1-9. http://www.revistavirtualia.com/articulos/767/coloquio-jacqueslacan-2001-en-buenos-aires/la-introduccion-a-la-antifilosofia.

Benjamin, W. (2016/1982). Libro de los pasajes (L. Fernández Castañeda, Trad.). Akal.

Bracher, M. (1994). On the Psychological and Social Functions of Language: Lacan's Theory of the Four Discourses. En M. Bracher, M. Alcorn, R. Corthell, \& F. Massardier-Kenney (Eds.), Lacanian Theory of Discourse Subject, Structure, and Society (págs. 107-128). New York University Press.

Deleuze, G. y Guattari, F. (2010/1973). El anti-Edipo. Capitalismo y esquizofrenia (F. Monge, Trad.). Paidós.

Derrida, J. (1995). Espectros de Marx. El estado de la deuda, el trabajo del duelo y la nueva internacional (J. M. Alarcón, \& C. De Peretti, Trads.). Trotta.

Dolar, M. (2017). Uno se divide en dos. Más allá de la interpelación (A. Torales, Trad.). Paradiso.

Faye, E. (2017). Il n'y a pas de rapport sexuel... Ou pire: the discourse of capitalism. Journal of the Circle for Lacanian Ideology Critique (10-11), 180-194. http://www.lineofbeauty.org/index.php/S/article/view/93.

Freud, S. (2000/1900). La interpretación de los sueños. En J. Strachey (Ed.), J. L. Etcheverry \& L. Wolfson (Trads.), Obras completas (Vol. V). Amorrortu. 
Freud, S. (2000/1905). Tres ensayos de teoría sexual. En J. Strachey (Ed.), J. L. Etcheverry \& L. Wolfson (Trads.), Obras completas (Vol. VII, págs. 109224). Amorrortu.

Freud, S. (2000/1911). Puntualizaciones psicoanalíticas sobre un caso de paranoia (Dementia paranoides) descrito autobiográficamente (Caso Schreber). En J. Strachey (Ed.), J. L. Etcheverry \& L. Wolfson (Trads.), Obras completas (Vol. XII, págs. 1-76). Amorrortu.

Freud, S. (2000/1914). Introducción del narcisismo. En J. Strachey (Ed.), J. L. Etcheverry \& L. Wolfson (Trads.), Obras completas (Vol. XIV, págs. 65-98). Amorrortu.

Freud, S. (2000/1920). Más allá del principio de placer. En J. Strachey (Ed.), J. L. Etcheverry \& L. Wolfson (Trads.), Obras completas (Vol. XVIII, págs. 1-62). Amorrortu.

Freud, S. (2000/1927). El porvenir de una ilusión. En J. Strachey (Ed.), J. L. Etcheverry \& L. Wolfson (Trads.), Obras completas (Vol. XXI, págs. 1-55). Amorrortu.

Freud, S. (2000/1930). El malestar en la cultura. En J. Strachey (Ed.), J. L. Etcheverry \& L. Wolfson (Trads.), Obras completas (Vol. XXI, págs. 57-140). Amorrortu.

Glynos, J. (2013). El capitalismo y el acto. Del contenido a la forma, ida y vuelta. En I. Parker, \& D. Pavón-Cuéllar (Coords.), Lacan, discurso, acontecimiento. Nuevos análisis de la indeterminación textual (págs. 179-192). UMSNH-Plaza y Valdés.

Goux, J.-J. (1996). The Coiners of Language (J. Curtiss, Trad.). University of Oklahoma Press.

Kojève, A. (2006/1982). La dialéctica del amo y el esclavo en Hegel (J. J. Sebreli, Trad.). Leviatán.

Kordela, K. (2007). \$urplus: Spinoza, Lacan. State University of New York Press. Lacan, J. (1967). Le Séminaire Livre XIV. La logique du fantasme. Staferla.

Lacan, J. (1978/1972). Du discours psychanalytique. En G. B. Contri (Trad.), Lacan in Italia / En Italie Lacan (págs. 26-51). La Salamandra.

Lacan, J. (2008/1968). El Seminario Libro 16. De un Otro al otro (N. González, Trad.). Paidós.

Lacan, J. (2009/1966). El seminario sobre La carta robada. En J. Lacan, Escritos (T. Segovia y A. Suárez Trads., Vol. I, págs. 23-72). Siglo Veintiuno Editores.

Lacan, J. (2009/1972). El Seminario Libro 20. Aún (D. Rabinovich, DelmontMauri, \& J. Sucre, Trads.). Paidós.

Lacan, J. (2010/1969). El Seminario Libro 17. El reverso del psicoanálisis (E. Berenguer, \& M. Bassols, Trads.). Paidós. 
Lacan, J. (2012/1971). El Seminario Libro 19 ...O peor (G. Arenas, Trad.). Paidós. Lacan, J. (2014/1970). Radiofonía. En Otros escritos (M. Álvarez, Trad., págs. 425-471). Paidós.

Lacan, J. (2015/1960). El Seminario Libro 8. La transferencia (E. Berenguer, Trad.). Paidós.

Laclau, E., y Mouffe, C. (2011/1985). Hegemonía y estrategia socialista. Hacia una radicalización de la democracia (E. Laclau, Trad.). Fondo de Cultura Económica.

Lombardi, G. (2015). La libertad en psicoanálisis. Paidós.

Luchelli, J. P. (2016). Le premier Lacan: cinq lettres inédites de Lacan à Kojève. Cliniques Méditerranéennes, 94(2), 297-308. https://doi.org/10.3917/ cm.094.0297

Marx, K. (2006/1867). El capital. Crítica de la economía política, Vol. I (W. Roces, Trad.). Fondo de Cultura Económica.

Marx, K. (2009/1844). Manuscritos de economía y filosofía (F. R. Llorente, Trad.). Alianza.

Marx, K. (2010/1845). La ideología alemana (W. Roces, Trad.). Colofón.

Milner, J-C. (2016/1995). La obra clara. Lacan, la ciencia, la filosofía (D. Rabinovich, Trad.). Manantial.

Moncayo, R. (2017). The Symbolic in the Early Lacan as a Cybernetic Machine, as Automaton and Tyché, and the Question of the Real. Journal of the Circle for Lacanian Ideology Critique (10-11), 245-260. http:/ / www. lineofbeauty.org/index.php/S/article/view/95/114.

Pavón-Cuéllar, D. (2009). Marxisme lacanien. Psychophores.

Pavón-Cuéllar, D. (2014). Elementos políticos de marxismo lacaniano. Paradiso.

Pavón-Cuéllar, D. (2017). Marxism and Psychoanalysis: In or Against Psychology? Routledge.

Pluth, E. (2020). Language and Discourse. En Y. Stavrakakis (Ed.), Routledge Handbook of Psychoanalytic Political Theory (págs. 221-232). Routledge.

Roudinesco, E. (1994). Lacan: Esbozo de una vida, historia de un sistema de pensamiento (T. Segovia, Trad.). Fondo de Cultura Económica.

Spinoza, B. (2011/1678). Ética. Demostrada según el orden geométrico (O. Cohan, Trad.). Gredos.

Tomšič, S. (2012). Homology: Marx and Lacan. Journal of the Circle for Lacanian Ideology Critique (5), 98-113. http:/ / www.lineofbeauty.org/index. php/S/article/viewFile/15/19.

Tomšič, S. (2015). The Capitalist Unconscious: Marx and Lacan. Verso.

Tomšič, S. (2019). The Labour of Enjoyment. Towards a Critique of Libidinal Economy. August Verlag.

Tomšič, S. (2020). Capitalism. En Y. Stavrakakis (Ed.), Routledge Handbook of Psychoanalytic Political Theory (págs. 296-306). Routledge. 
Wajcman, G. (2001). El arte, el psicoanálisis, el siglo. En F. Regnault, \& G. Wacjman (J. J. Utrilla Trejo, Trad.), Lacan: el escrito, la imagen (págs. 4173). Siglo Veintiuno Editores.

Zevnik, A. (2016). Lacan, Deleuze and World Politics Rethinking the Ontology of the Political Subject. Routledge.

Žižek, S. (2004). El Homo Sacer como objeto del discurso de la universidad. En Y. C. Zarka (Ed.) \& I. Agoff (Trad.), Jacques Lacan. Psicoanálisis y politica (págs. 33-50). Nueva Visión.

Žižek, S. (2010). El sublime objeto de la ideología (I. Vericat Nuñez, Trad.). Siglo XXI.

Žižek, S. (2012). Menos que nada. Hegel y la sombra del materialismo dialéctico (A. Antón Fernández, Trad.). Akal.

Žižek, S. (2013). El resto indivisible (A. Bello, Trad.). Ediciones Godot.

Zupančič, A. (2006). When Surplus Enjoyment Meets Surplus Value. En J. Clemens, \& R. Grigg (Eds.), Jacques Lacan and the Other Side of Psychoanalysis. Reflections on Seminar XVII (págs. 155-178). Duke University Press.

Zupančič, A. (2013). La sexualidad dentro de los límites de la mera razón. En M. Dolar, S. Žižek, \& A. Zupančič (M. Orvañanos, Trad.), Ardillas a las bellotas: entre psicoanálisis, filosofía y el cine de Ernest Lubitsch (págs. 43-70). Paradiso. 